\title{
HYBRIDE IRRADIATION AS BEST AVAILABLE PRACTICE IN ARTIFICIAL PLANT LIGHTING
}

\author{
Sergey Rakutko ${ }^{1}$, Ansis Avotins ${ }^{2}$, Juris Gruduls ${ }^{3}$, Elena Rakutko ${ }^{1}$ \\ ${ }^{1}$ Institute for Engineering and Environmental Problems in Agricultural Production, Russia; ${ }^{2}$ Riga \\ Technical University, Latvia; ${ }^{3}$ Latgales Dārzeṇu Logistika, Latvia \\ sergej1964@yandex.ru
}

\begin{abstract}
Growing of plants in artificial lighting conditions require a certain irradiation spectrum. High-pressure sodium (HPS) lamps are the cheapest way to generate optical radiation. However, their light quality is not fully suitable for plants. Light-emitting diodes (LEDs) allow for almost any light quality, but they are still more expensive than HPS lamps. The study objective was to identify the light quality of a LED spectrum corrector used to complement HPS lamps in artificial plant lighting and to prove the practical relevance of this solution in the laboratory and commercial greenhouse conditions. A comparative laboratory experiment was carried out on tomato (Solanum Lycopersicum L.) transplants, Blagovest F1 cultivar, in IEEP (Saint Petersburg, Russia). The use of the spectrum corrector improved the transplants biometrics: increased number of leaves and their fresh mass, higher chlorophyll and dry matter content. A greenhouse experiment was carried out in Mezhvidi (Latgalia, Latvia) on mature tomato plants of Encore cultivar in three variants: under HPS lamps, under Phillips LED irradiators, and under the irradiators combining HPS lamps and the spectrum corrector. The effect of the irradiator type on the plants was assessed by the plant developmental stability estimated by the fluctuating asymmetry $(F A)$ of the leaf bilateral traits. The least favourable light environment with the maximum fluctuating asymmetry was found under HPS lamps $\left(F A_{\text {avg }}=0.1064\right.$ rel. units). LED irradiators created better conditions for plant development $\left(F A_{\text {avg }}=0.0767\right.$ rel. units $)$. The use of the spectrum corrector provided the best light environment $\left(F A_{a v}=0.0659\right.$ rel. units). Under the combined irradiation, a higher yield and improved taste of tomato fruits were recorded. The experiment results prove the hybrid irradiation to improve the artificial plant lighting efficiency.
\end{abstract}

Keywords: light quality, spectrum corrector, hybrid irradiation.

\section{Introduction}

Conventional greenhouse lighting systems use broad-spectrum light sources, such as highpressure sodium lamps (HPS). LEDs reduce the artificial lighting costs by $25 \%$ compared to traditional artificial lighting costs owing to their higher electrical conversion efficiency of $75 \%$ [1]. The photosynthetically active radiation (PAR) has the major effect in this respect. The radiation effect is governed by the light quality defined usually by the wavelengths in PAR spectral bands: blue $k_{B}$ $(400-500 \mathrm{~nm})$, green $k_{G}(500-600 \mathrm{~nm})$ and red $k_{R}(600-700 \mathrm{~nm})$. The far-red radiation $k_{F R}(700-$ $780 \mathrm{~nm}$ ) is specified individually.

The effect of radiation in different spectral bands on the growth and development of plants is well understood. It is known that blue light inhibits hypocotyl lengthening, promotes biomass production, leaf development, stomata opening, and chloroplast movement through activation of phototropin in higher plants [2]. Both blue and red light are most important in LEDs application as they stipulate the growth of plant biomass and fruit production [3]. It is reported that HPS lamps complemented with blue radiation yield higher overall biomass, but a lower number of cucumbers and tomatoes [4]. The ratio of blue and red radiation affects the stem length of tomato seedlings [5]. The red radiation contributes to longer hypocotyl and bigger leaf area [6]. The studies of plant growth, photosynthesis, and productivity proved the spectral ratio $k_{B}: k_{G}: k_{R}=30 \%: 20 \%: 50 \%$ to be the most favorable for light-demanding crop cultivation. The ratios $k_{R}: k_{B}$ and $k_{R}: k_{F R}$ are also analysed to estimate the spectrum efficiency. A low $k_{R}: k_{F R}$ ratio causes a set of plant responses known as a shade-avoidance syndrome. It includes elongation of internodes, petioles, and leaves, increased apical dominance, reduced branching, and accelerated flowering. In contrast, a high $k_{R}: k_{F R}$ ratio causes physiological reactions resulting in a compact plant crown [7].

The traditional approach to ensuring the lighting regime of plants is HPS lamps, one of the most energy-efficient light sources. Their light quality in the visible region, which coincides with PAR, consists of self-reversed and strongly broadened sodium D-lines $(589.0$ and $589.6 \mathrm{~nm}$ ), with $70 \%$ of the visible radiation being concentrated in the yellow-orange spectrum band (560-610 nm). In a 1000 W HPS lamp, about $27 \%$ of the consumed electric energy is converted into PAR, with $14 \%$ accounting for 400 to $565 \mathrm{~nm}$ wavelengths, and the rest - up to $700 \mathrm{~nm}$ wavelengths [8]. 
The photon efficacy of a PAR flux of modern HPS lamps is up to $1.7 \mu \mathrm{mol} \cdot \mathrm{J}^{-1}$ at significant service life. However, such light quality does not fully satisfy the plant requirements [9]. In contrast to broadband gas-discharge sources, LED irradiators can provide almost any light quality of cumulative radiation through selecting the required LED types and adjusting their power supply mode [10]. Modern LEDs have photon efficacy around $2.7 \mu \mathrm{mol} \cdot \mathrm{J}^{-1}$ or more. The common disadvantage of LEDbased installations is their high cost, material consumption of the heat-sink and the weight of the irradiator. However, the costs tend to reduce. According to some estimates, LED irradiators still are not able to replace HPS lamps in the industrial greenhouse lighting $[11 ; 12]$.

Today the combined (hybrid) irradiation facilities seem to be a rational solution when relatively cheap HPS lamps generate the main radiation flux and LEDs supply the deficiency in certain spectral bands. The available literature does not provide much information on the hybrid lighting systems for growing tomatoes. In the experiment [13] three lighting systems were compared: 1) HPS lamps, 2) LEDs, and 3) a hybrid system, where the radiation flux was equally divided between HPS lamps and LEDs, with $12 \%$ blue $(450 \mathrm{~nm})$ and $88 \%$ red $(660 \mathrm{~nm})$ LEDs being used. The irradiation at the top of the plants was set equal. The leaves of tomato plants grown only under HPS lamps were thinner and grew old earlier than in other variants. The photosynthesis under LEDs and the hybrid irradiation was higher than that under HPS lamps. The difference in productivity turned out to be small; under LEDs, the productivity was smaller. The difference in product quality was not revealed.

In the experiment [14], two irradiation systems were compared: 1) HPS lamps and 2) a hybrid system. Plants grown under the hybrid system had the same stem length, more trusses, greater growth power identified by the stem thickness at the plant top, and a larger tomato fruit mass. The yields were about $20 \%$ bigger, but the energy inputs were also higher by $34 \%$. It was noted that to reduce the energy intensity of production and to achieve the greater energy efficiency of the hybrid irradiation system was possible by optimizing the cultivation techniques and lighting strategies.

Our patent search identified the suitable modern technical solution from Phillips Company, the world's leading producer of greenhouse radiation sources, - a plant irradiation system that included a HPS lamp supplementing the natural radiation and separate blue and far-red LEDs [15]. However, the closer consideration revealed the separately installed LEDs to be a drawback of this solution, as they required a separate control system, increased the system cost and reduced the efficiency of indoor plant lighting in general.

The study objective was to identify the light quality of a LED spectrum corrector used to complement the HPS lamps in the indoor plant lighting and to prove the practical relevance of this solution in the laboratory and commercial greenhouse conditions.

\section{Materials and methods}

The study used a spectrum corrector with COB LEDs designed by Science and Production Amalgamation "Pskovagroinnovations" (Russia) [16]. Fig. 1 shows the design and components of the spectrum corrector.
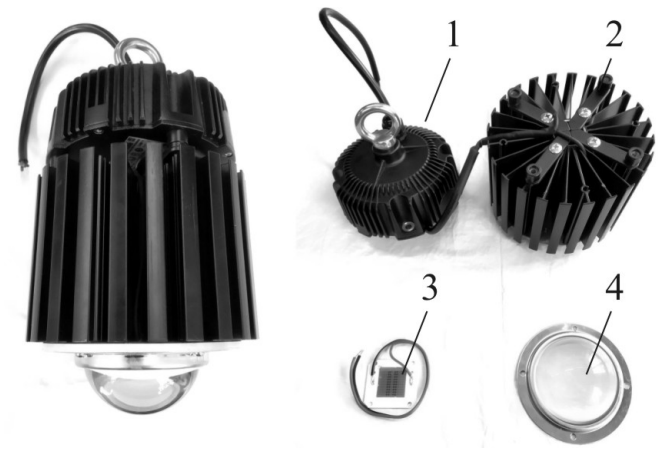

Fig. 1. Design and components of the spectrum corrector: 1 - driver, 2 - heat-sink, 3 - LED matrix, 4 - lens

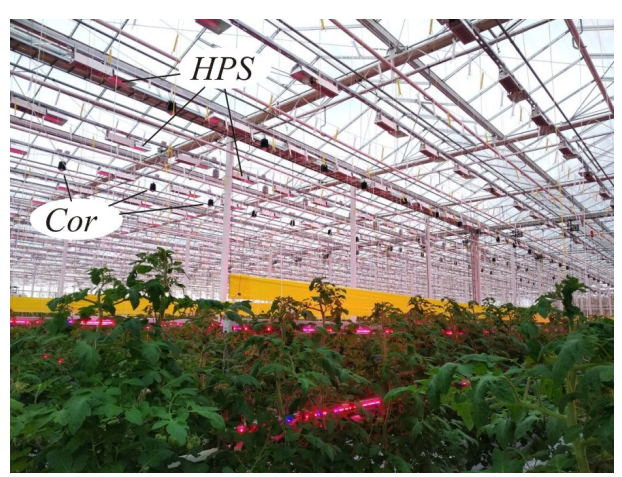

Fig. 2. Hybrid irradiation facility in the greenhouse 
The corrector received the electrical power from the HBG-100-24 driver 1 attached above the heat-sink 2 with the spacers. The LED matrix 3 consisted of a defined ratio of crystals with required spectral bands. It was attached below the heat-sink 2 by a thermal conducting paste. The matrix was hermetically sealed by the 90 -degree dispersing lens 4 . The required light quality of the matrix was calculated taking into account the light quality and radiation intensity of a 400W HPS lamp to adjust the lighting to the crop requirements.

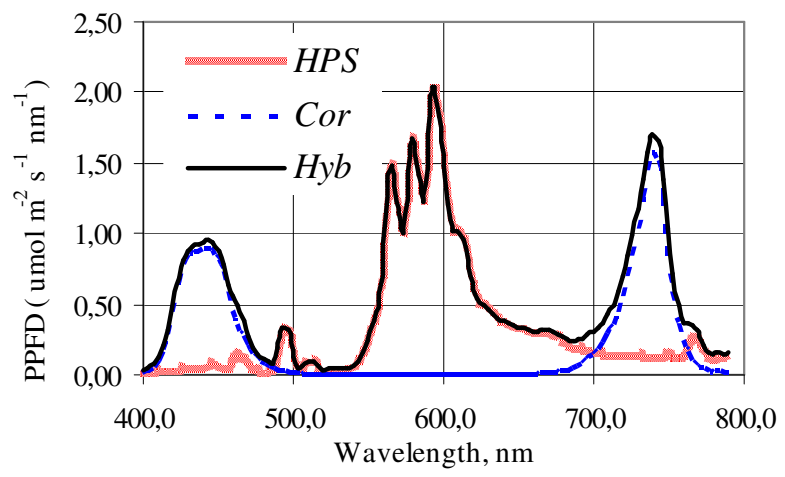

Fig. 3. Light quality of a sodium lamp (HPS), a spectrum corrector (Cor) and the combined flux $(\mathrm{Hyb})$

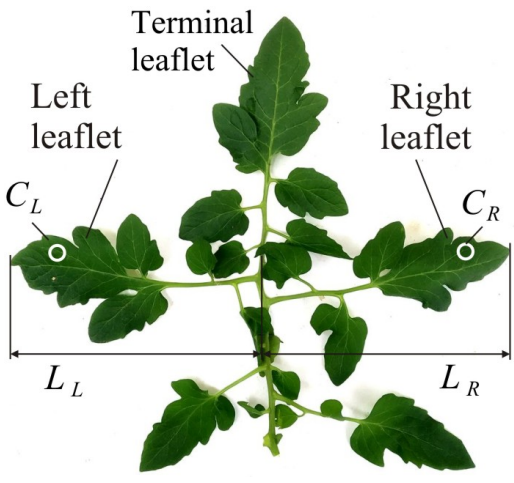

Fig. 4. Measured bilateral traits of the tomato compound leaf

As already mentioned, the HPS lamps emitted a small energy portion in the blue spectrum, a very big portion in the green spectrum and an insufficient portion in the red and far-red spectra (HPS curve in Fig. 3). The ratio $k_{R}: k_{B}$, which should be close to 1.7 rel. units in the optimal spectrum, was 6.2 rel. units average for different wattage lamps. The ratio $k_{R}: k_{F R}$, which should be around 2.0 rel. units, was 3.8 rel. units average, i.e. there was a critical energy deficiency in the blue and far-red spectrum bands. Therefore, the corrector matrix should include the crystals with these spectrum bands. The simulation results showed that for the DNaT 400 lamp, a photon flux of the corrector matrix of $71.2 \mu \mathrm{mol}^{-1} \mathrm{~s}^{-1}$ was required, with the ratio of blue and far-red crystals being $k_{B}: k_{F R}=64 \%: 36 \%$. Figure 3 shows the light quality of the corrector matrix (curve Cor) and the resulting combined flux $(H y b)$ with the equal number of HPS and correctors in the irradiation facility.

The hybrid irradiation effectiveness was estimated in the laboratory study on tomato transplants (Solanum Lycopersicum L.). A comparative experiment was carried out in the dark room, where tomato transplants of Blagovest F1cultivar were grown. The control and experimental irradiation facilities were placed in two different zones of the room, which were separated by a lightproof curtain. The control irradiation facility consisted of two irradiators with HPS lamps joint by the side surfaces so that the lamps were pointed in the opposite directions. The experimental irradiation facility was similar to the control irradiation facility, but a rod with two spectrum correctors was added to the perpendicular axis. The standard transplant biometrics were measured. The experiments had three replications. The average biometric parameters were calculated per five plants in each replication.

The irradiation effect on mature tomato plants of Encore cultivar was assessed in the greenhouse Mezhvidi (Latvia) in three testing options: 1) under HPS lamps Master Green Power CG 230V 400W (PPF $725 \mu \mathrm{mol}^{-1}$ ), 2) under LED irradiators Phillips GreenPower DR/B LB 400V 190W (PPF 440 $\left.\mu \mathrm{mol} \mathrm{s}^{-1}\right), 3$ ) under combined radiation. The intracanopy lighting was used in all options, two rows of GreenPower DR/B LB 230V 115W irradiators (Fig. 2). The assessment was based on the developmental stability of plants expressed by the fluctuating asymmetry of bilateral traits (FA) of a leaf blade. In our preliminary experiments, the influence of the light medium parameters on FA was revealed [17].

Two bilateral traits were analysed statistically: 1) the lengths of the first right-side and left-side leaflets from the terminal leaf of a compound tomato leaf $\left(L_{L}\right.$ and $\left.\left.L_{R}\right) ; 2\right)$ the leaf chlorophyll content $\left(C_{L}\right.$ and $\left.C_{R}\right)$ (Fig. 4). Fluctuating asymmetry was calculated by the formula:

$$
F A=\frac{1}{N} \sum_{i=1}^{N} \frac{\left|B_{L}^{i}-B_{R}^{i}\right|}{2 \cdot\left(B_{L}^{i}+B_{R}^{i}\right)},
$$


where $i-$ the plant number;

$N$ - the number of measurements;

$B$ - the bilateral trait.

The chlorophyll content was determined by a CCM-200 meter (Opti-Science, USA) in relative units. The data were analysed by the mathematical statistics methods $(p<0.05)$ using Excel 2003 and Statistica 6.0 software packages. ANOVA was applied to analyse the statistical differences. The least significant difference $(L S D)$ at the 0.95 level $(p \leq 0.05)$ was used to compare the mean values by Fisher's test.

\section{Results and discussion}

The laboratory experiment showed that the hybrid irradiation improved the biometric parameters of tomato transplants. The leaf number increased by $7.1 \%$; the stocky transplants were stronger and $20 \%$ shorter; the leaf chlorophyll content increased significantly; the leaves had $2.8 \%$ bigger fresh mass and $10.5 \%$ higher dry matter content.

Chlorophyll is a key biochemical component of the molecular apparatus involved in photosynthesis, the process by which the light energy accumulates in the organic matter of plants. Chlorophyll is usually found in thylakoid membranes of chloroplasts. It governs the photosynthetic efficiency as well as the plant growth and their adaptability to environmental conditions.

The photosynthetic intensity depends on two types of factors - the external factors, including lighting conditions, and the internal ones, including the chlorophyll content. The chlorophyll content in the leaves varies with the plant genetics, mineral elements content, environmental factors, etc. This is a direct indicator of the plant health and status.

The non-destructive analysis of the plant chlorophyll content provides researchers and agronomists with very useful diagnostic information for nutrient assessment, irrigation management, pest control, environmental stress assessment, and plant breeding. The procedure is well developed for the main field crops and leafy vegetables. According to our previous studies, the asymmetry of the chlorophyll content in the symmetrical leaf parts of a tomato plant can be used to assess the plant developmental stability [17].

When considering the effect of the light source type on the developmental stability of tomato plants, a certain tendency can be seen (Fig. 5).

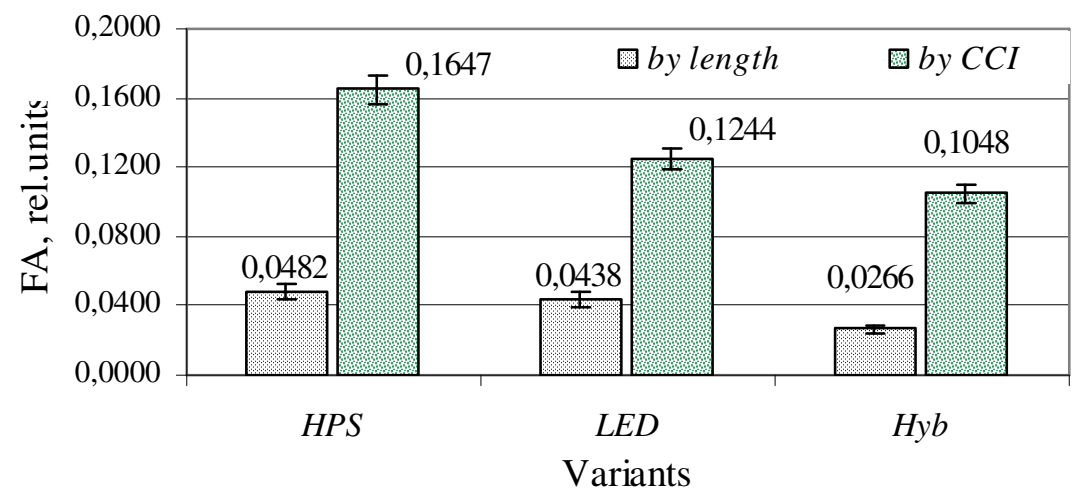

Fig. 5. FA level calculated by the leaflets length and the chlorophyll content for different types of light sources

It can be stated that HPS lamps formed the least favourable light environment. FA calculated by the leaf length was $F A_{L}=0.0482$ rel. units; FA calculated by the chlorophyll content was $F A_{C}=0.1647$ rel. units; the average FA was $F A_{\text {avg }}=0.1064$ rel. units. In the assessment, these values were taken as $100 \%$.

According to the experiment results, Phillips LED irradiators improved the developmental stability of plants by $9 \%$ in terms of the leaf length $\left(F A_{L}=0.0438\right.$ rel. units), by $25 \%$ in terms of the chlorophyll content $\left(F A_{C}=0.1244\right.$ rel. units $)$, and in average by $17 \%$ ( $F A_{\text {avg }}=0.0767$ rel. units). The hybrid irradiation versus HPS lamps improved the developmental stability of plants by $45 \%$ in terms 
of the leaf length $\left(F A_{L}=0.0266\right.$ rel. units $)$, by $36 \%$ in terms of the chlorophyll content $\left(F A_{C}=0.1048\right.$ rel. units), and in average by $40 \%\left(F A_{\text {avg }}=0.0659\right.$ rel. units. $)$. The high yield of tomato fruits and their improved taste were also observed under the hybrid irradiation. The research in this direction finally aims at the creation of the best available techniques of the artificial plant lighting by the criterion of energy and environmental compatibility as a complex criterion of optimality. The proposed approach and the promotion of the hybrid irradiation will achieve the maximum effect of upgrading and reequipment of greenhouses [18].

Modern greenhouses widely apply intensive crop cultivation under HPS lamps. Its undoubted advantage is that this is a well-established practice over a long time. The disadvantage of these lamps is the low radiation efficiency of PAR and rather an insufficient light quality. In recent years, LED irradiators have been actively promoted. Though they have a more relevant light quality, the replacement practice of HSP lamps with LEDs in the top lighting has not been still widely introduced in industrial greenhouses. There are two main reasons for this: the many-fold higher cost and, most importantly, the lack of appropriate plant growing technologies. Simply replacing HPS lamps with LEDs changes the energy balance in the greenhouse.

To date, there has not been developed yet a comprehensive solution to the problem of transition to LEDs. This study proposed and implemented a method to adjust the spectrum of the commonly used additional HPS lamp-based lighting system in the greenhouse complexes by complementing the insufficient spectral bands with special devices. The use of a hybrid irradiation system is the best available technique (BAT) for the artificial plant lighting. It significantly increases the efficiency of light energy use by cultivated plants leading to shorter pre-fruiting period, higher plant productivity, improved commercial quality of fruits and higher sugar and vitamin content in them.

The combination of the HPS lamps economic efficiency and the high quality of the resulting photon flux will both result in higher yields, and have more global effects: reduced energy inputs and heat and $\mathrm{CO}_{2}$ emissions; improved efficiency and environmental friendliness of protected plant cultivation. The hybrid system, which combines HPS lamps and LEDs, takes advantage of both systems and shows great promise in this respect.

In the study, only the blue and far-red LEDs improved the light quality. The considered spectral relations suggest the absence of a natural component of irradiation. If the solar radiation is included, its contribution needs to be taken into account and the control of the spectrum corrector is to be subsequently adjusted.

\section{Conclusions}

1. The study developed a method of adjusting the light quality of a traditional HPS lamp-based lighting system in a greenhouse by complementing the insufficient spectral bands with special devices - spectrum correctors.

2. The study justified the parameters of the spectrum corrector, which generated the flux only in the insufficient blue and far-red bands in a ratio of $64 \%$ and $36 \%$, respectively. Its total flux was selected according to the used lamp wattage, and for the DNaT 400 lamp it was $71.2 \mu \mathrm{mol}^{-1} \mathrm{~s}^{-1}$

3. The study revealed the positive biological effect of the hybrid irradiation on tomato transplants, which demonstrated significantly improved biometric indicators.

4. The estimates by different biometrics revealed that the developmental stability of mature tomato plants grown in the greenhouse improved by $36-45 \%$.

\section{Acknowledgements}

The publication was supported by the European Regional Development Fund project "New control methods for energy and ecological efficiency increase of greenhouse plant lighting systems (uMOL)", Grant Agreement Nr. 1.1.1.1/16/A/261.

\section{References}

[1] Gomez C., Morrow R., Bourget C.B. etc. 2013. Comparison of intracanopy light-emitting diode towers and overhead high pressure sodium lamps for supplemental lighting of greenhouse grown tomatoes. HortTechnology, vol. 23, 2013, pp. 93-98. 
[2] Boccalandro H., Giordano C., Ploschuk E. etc. 2012. Phototropins but not cryptochromes mediate the blue light-specific promotion of stomatal conductance, while both enhance photosynthesis and transpiration under full sunlight. Plant Physiol., vol. 158, 2012, pp. 1475-1484.

[3] Xiaoying L., ShiRong G., TaoTao C. etc. Regulation of the growth and photosynthesis of cherry tomato seedlings by different light irradiations of light emitting diodes (LED). Afr. J. Biotechnol., vol. 11, 2012, pp. 6169-6177.

[4] Menard C., Dorais M., Hovi T. etc. Developmental and physiological responses of tomato and cucumber to additional blue light. Acta Hort., vol. 711, 2006, pp. 291-296.

[5] Nanya K., Ishigami Y., Hikosaka S. etc. Effects of blue and red light on stem elongation and flowering of tomato seedlings. Acta Hort., vol. 956, 2012, pp. 261-266.

[6] Johkan M., Shoji K., Goto F. etc. Effect of green light wavelength and intensity on photomorphogenesis and photosynthesis in Lactuca sativa. Environmental and Experimental Botany, vol. 75, 2012, pp. 128-133.

[7] Протасова Н.Н. Светокультура как способ выявления потенциальной продуктивности растений (Plant lighting as a way to identify potential plant productivity). Физиология растений. Russian Journal of Plant Physiology, 1987, № 34 (4). (In Russian).

[8] Nelson J.A., Bugbee B. Economic analysis of greenhouse lighting: light emitting diodes vs. high intensity discharge fixtures. PLoS ONE, vol. 9(6), 2014, e99010.

[9] Wheeler R.M. A historical background of plant lighting: an introduction to the workshop. HortScience, vol. 43(7), 2008, pp. 1942-1743.

[10] Folta K.M., Koss L.L., McMorrow R. etc. Design and fabrication of adjustable red-green-blue LED light arrays for plant research. BMC Plant Biology, vol. 5, 2005, pp. 17.

[11]Прикупец Л.Б., Емелин А.А., Тараканов И.Г. Светодиодные облучатели: из фитотрона в теплицу? (LED irradiators: from a phytotron to a greenhouse?). Теплицы России. Greenhouses of Russia, 2015, №2, C. 52-56. (In Russian).

[12]Пчелин В.М., Макарова И.Е. Об экономической целесообразности массового внедрения светодиодов в тепличном освещении в настоящее время (On the economic feasibility of the mass adoption of LEDs in greenhouse lighting today). Теплицы России. Greenhouses of Russia , 2017, №4, C. 62-66. (In Russian).

[13] Dueck T.A., Janse J., Eveleens B.A. etc. 2012. Growth of tomatoes under hybrid LED and HPS lighting. Acta Hortic., vol. 952, 2012, pp. 335-342.

[14] Moerkensa R., Vanlommel W., Vanderbruggen R. etc. 2016. The added value of LED assimilation light in combination with high pressure sodium lamps in protected tomato crops in Belgium. Acta Hortic., vol.16, 2016, p. 1134.

[15] Крейн М. Системы и способы освещения растений (Systems and methods for plant lighting). Заявка: 2017137737, 31.03.2016. Дата публикации заявки: 30.04.2019. Бюл. № 13. Application Patent of the Russian Federation. (In Russian).

[16] Аюпов М.Р., Ракутько С.А. О возможности коррекции спектра натриевой лампы с помощью светодиодного источника под требования светокультуры (LED-based correction of sodium lamp light quality for indoor plant lighting demands). Технологии и технические средства механизированного производства продукции растениеводства и животноводства. Technologies, machines and equipment for mechanised crop and livestock production, 2018, № 94, C. 5-13. (In Russian).

[17] Rakutko S., Alsina I., Avotins A. etc. Manifestation of effect of fluctuating asymmetry of bilateral traits of tomato growing in industrial greenhouses. Proceedings of International conference "Engineering for rural development", 2018, pp. 186-191.

[18] Ракутько С.А. Энергоэкологические основы наилучших доступных технологий светокультуры (Energy and ecological basis of best available techniques of plant lighting). Технологии и технические средства механизированного производства продукции растениеводства и животноводства. Теchnologies, machines and equipment for mechanised crop and livestock production. 2019, № 1(98), C. 44-60. (In Russian). 